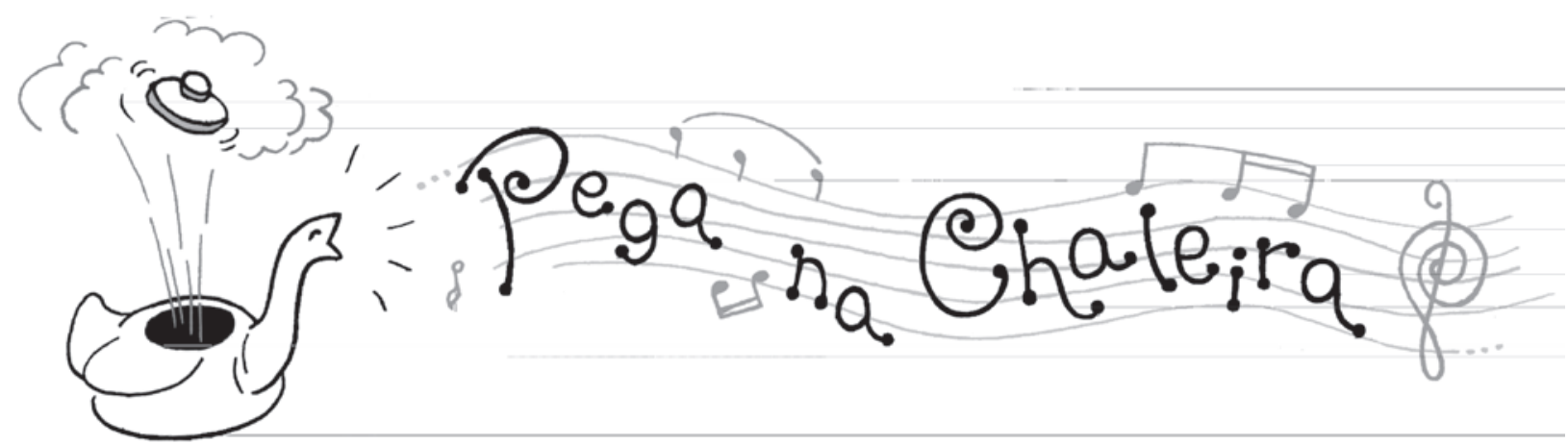

PEGA NA CHALEIRA - RESENHAS

\title{
Resenha sobre Eu não sou cachorro, não, livro de Paulo Cesar de Araújo sobre a música cafona
}

\author{
Fausto Borém (UFMG, Belo Horizonte, MG) \\ fborem@ufmg.br
}

\section{Review of Eu não sou cachorro, não, Paulo Cesar de Araújo's book on Brazilian cafona music}

ARAÚJO, Paulo Cesar de. Eu não sou cachorro, não: música popular cafona e ditadura militar. Rio de janeiro: Record, 2010. 7. Ed. 458p. Preço médio de $\mathrm{R} \$ 40$.

Estar fora do círculo tradicional dos musicólogos e etnomusicólogos das universidades talvez tenha facilitado o olhar independente e contundente de Paulo Cesar de Araújo sobre um período histórico da música de mercado brasileira. Professor do Ensino Fundamental, Paulo Cesar há muito se pergunta por que as letras de canções brasileiras utilizadas em livros didáticos ignoram expressiva parcela de compositores com os quais a maioria da população brasileira - e não apenas as elites - se identifica. Com sua escrita ao mesmo tempo didática e atraente, bemhumorada e engajada, surpreendente e pitoresca em cada página, ele parte de sua minuciosa revisão de literatura e entrevistas, masgistralmente organizadas para fundamentar suas inferências, em quase 500 páginas,
"O livro Eu não sou cachorro, não tá colocando ordem e fazendo justiça na música brasileira. Ele resgata e explica a importância desses artistas que eram execrados pela crítica, mas adorados pelo povão, porque faziam música que falavam da vida e dos sentimentos dos brasileiros de uma forma que todos entendiam." MOTA (2010) 
de artistas e personagens das músicas, e reprodução de documentos do Serviço de Censura da Polícia Federal. Uma das diversas e relevantes contribuições do autor nesse livro é apontar, no meio musical, uma replicação do modelo do regime autoritário dos militares, mostrando como jornalistas, críticos, pesquisadores, produtores e, mesmo, alguns artistas mais letrados subjugaram artistas de classes sociais menos favorecidas, ou vindos do interior ou de regiões como o Nordeste. Revela como buscaram calar o fenômeno da música cafona em alguns círculos mais cultos por meio da exclusão, do silêncio, do preconceito. Detentores do poder nos meios de comunicação e órgãos públicos, alguns formadores de opinião e insuspeitos representantes das patrulhas ideológicas foram eficientes: forjaram verdades, publicaram enciclopédias incompletas, organizaram fontes de referência faltosas. Como foi o caso da coleção História da música popular brasileira, vendida em bancas de jornal, ou do acervo de entrevistas do MIS (Museu da Imagem e do Som) do Rio de Janeiro, cujos dirigentes ou curadores se omitiram sobre este segmento artístico da nossa música. Ao final, tem-se a nítida impressão de uma segregação no seio da música popular, dividindo o Brasil em dois opostos, refletindo o que era o país nos tempos da ditadura: um oficial e conhecido; o outro "inexistente". Mas que agora podemos conhecer.

No primeiro capítulo, Um alfaiate no centro da polêmica (Paulo Sérgio x Roberto Carlos), [p.25-33] Paulo Cesar traz de volta os bastidores do duelo entre dois dos maiores ídolos de massa de todos os tempos no Brasil. 0 primeiro, hoje esquecido pela história oficial da música brasileira, mas não pelos fãs ardorosos. 0 segundo, tratado como rei e objeto de outra pesquisa do autor que também resultou em livro magnífico, mas cuja venda continua proibida. Ao mesmo tempo, Paulo Cesar traça, nesse capítulo, um perfil das três gerações de músicos "cafonas" da canção brasileira, a geração que despontou no fim dos anos de 1960 e chegou ao sucesso num período de forte radicalização da ditadura militar, a partir da decretação do Al-5, em 1968.

No capítulo Como uma sonda em marte (Nelson Ned e os cantores no ano de 1968) [p.35-50], o autor procura responder à pergunta "E onde estariam os cantores 'cafonas' naquela noite de sexta-feira, 13 de dezembro de 1968?", em que foi decretado o Al-5. Os entrevistados (Odair José, Benito de Paula, Claudio Fontana, Wanderlei Cardoso, Wando, Agnaldo Timóteo, Don e Ravel, Waldik Soriano, Nelson Ned), cuja maioria é de origem humilde e/ou do interior, revelaram que estavam ocupados demais tentando sobreviver de música na cidade grande no início de suas carreiras, sem a possibilidade de se engajarem politicamente naquele momento. 0 que não impediu que muitos deles se tornassem, mais tarde, pioneiros na discussão de tabus, arautos de diversas causas dos oprimidos e, mesmo, críticos do regime militar.

Em diversos capítulos do livro [Reinado de terror e virtude (Odair José na mira da repressão), p.51-68; Tortura de amor (Waldik Soriano e os porões da ditadura), p.69-82; Um
Grande açoitando um pequeno (a dupla Dom \& Ravel sob censura), p.83-100; Pederastas, maconheiros e prostitutas (Agnaldo Timóteo perdido na noite), p.131-152; Capricho dos instintos insaciáveis (Lindomar Castilho na luta pelo divórcio), p.153-173; Sexo, xixi e cocô (cantores do rádio na era da TV), p.297-316; Os Sons que vem da cozinha (Odair José e o apartheid brasileiro), p.317-334], Paulo Cesar mostra como os artistas cafonas é que foram pioneiros, e bravos o suficiente para enfrentarem a censura oficial, na abordagem de temas tabus ou "pouco-artísticos", geralmente evitados pelos compositores e intérpretes da MPB daquela época, como dogmas religiosos, homossexualidade, drogas, controle de natalidade, amor livre, crimes, prostituição, divórcio, a primeira experiência sexual, orgasmo, racismo, os direitos das empregadas, deficientes físicos, o preconceito contra imigrantes nordestinos, pobres, mendigos, meninos de rua, os semterra, abusos ou negligências da polícia, entre outros.

Um Grande açoitando um pequeno (a dupla Dom \& Ravel sob censura) [p.83-100] relata como essa dupla de irmãos, autora de músicas a favor dos sem-terra, ficou marcada como "adesistas" da ditadura por causa do sucesso de Eu te amo meu Brasil. A trajetória inglória de Dom \& Ravel é retomada em dois outros capítulos. No capítulo De armas, bandeiras e lápis nas mãos (ufanismo e guerrilha nos anos de chumbo) [p.211-231], essa dupla de irmãos cantores e também Wilson Simonal são transformados em bodes expiatórios dentro de um fogo cruzado entre regime e oposição que, se conseguiu destruir suas carreiras, poupou colegas como Zé Keti, Jorge Benjor, João Nogueira e os irmãos Marco e Paulo Sérgio Valle, que também fizeram canções ufanistas na época da ditadura. Já em No país dos mortos-vivos (Dom \& Ravel e as patrulhas ideológicas) [p.269-295], aprendemos que além do "coveiro" Henfil, que não perdoou nem Elis Regina, outros patrulheiros de plantão como Tárik de Souza, Ana Maria Bahiana, Margarida de Autran, Maria Helena Dutra, José Ramos Tinhorão e Maurício Kubrusly tiveram um papel predatório significativo nesse processo histórico. Há surpresas, como a birra do editor da Enciclopédia da música brasileira (1977), Paulo Sérgio Machado, que deixou Ivan Lins de fora dessa emblemática obra de referência por ter composto uma canção chamada 0 Amor é o meu país. Outra surpresa é o fato de que, em função da livre expressão enquanto artista, não Geraldo Vandré, mas Dom \& Ravel é que foram torturados e impedidos de exercerem a profissão.

Em dois capítulos seguidos, Paulo Cesar se detém mais sobre a "linguagem de fresta", utilizada para protestar e, ao mesmo tempo, driblar a censura oficial. 0 capítulo Tributo a um rei esquecido (Benito de Paula à procura de Geraldo Vandré) [p.101-115] traz o lado protestador desconhecido de Benito de Paula, Odair José e Lindomar Castilho e seus problemas com a censura em Brasília. Já no capítulo 0 Samba dos 13 anos (Wando e Luiz Ayrão contra o regime militar) [p.117-129], ele revela como o preconceito de esquerda levou os estudantes universitários engajados na luta contra a ditadura a ignorar as canções politicamente combativas de Luis Ayrão e Wando. 
Eis o início do capítulo Um Cantor chamado cavalo (artistas populares e crítica musical) (p.177-178): "Nos anos [de 19]70 era assim: todo mundo pichava todo mundo". Literalmente. E o autor explica porque: "Ainda não havia se instalado a ditadura do politicamente correto". Mas o clima de ditadura já havia se instalado há quase uma década no inconsciente coletivo do brasileiro, que parecia propenso a cumprir o ditado "diga-me com quem andas e te direi quem és". Não parecia haver limites ou credos para se exercer o autoritarismo no meio artístico, como no seguinte dominó de indelicadezas entre colegas, listado por Paulo Cesar de Araújo: "Waldik Soriano pichava Gilberto Gil, que pichava Wilson Simonal, que pichava Nara Leão, que pichava Tim Maia, que pichava Raul Seixas, que pichava Egberto Gismonti, que pichava Paulinho da Viola, ${ }^{2}$ que pichava Zé Keti, que pichava Pixinguinha, que pichava todo mundo. Sim, o 'santo' Pixinguinha não ficou imune à quela 'era do piche' ". De fato, pichou, entre outros, Martinho da Vila e Chico Buarque, que pichou Juca Chaves e os baianos da "falecida" Tropicália. Se o vale-tudo entre os artistas ainda pode ser minimizado por refletir apenas invejas e ciúmes, a destrutividade de formadores de opinião como intelectuais, críticos, produtores, jurados e apresentadores de programas de rádio e TV desempenhou papel fundamental para influenciar o público de classe média a marginalizar os artistas bregas.

No capítuloTransando com Deus e com o lobisomem (relações entre o "chique" e o "cafona") [p.197-210] aprendemos sobre o início do período musical asséptico que se instalou na Rede Globo, ilustrado pelo filtro imposto por idealizadores de programas como o Som Livre Exportação, cujo "livre" recebe merecidas aspas no livro (". . . Paulo Sérgio e Waldik Soriano não entram, porque são mentirosos, e o público não quer mais mentiras.") ou a grande e orquestrada vaia com que o público massacrou Agnaldo Timóteo (". . . aqueles meninos de classe media que só usam tênis importados dos Estados Unidos e pensam que são comunistas", desabafou o cantor). Já no programa Phono 73, as vaias foram para Odair José, convidado para cantar com Caetano Veloso. Este respondeu na hora com a histórica frase "Nada mais Z do que um público classe A", e desabafou mais tarde ". . . um público elitista que rejeita a música consumida por gente tida como pobre e ignorante. É casa-grande e senzala". Essa assepsia nos meios de comunicação chegou a tal ponto que, no capítulo Sexo, xixi e cocô (cantores do rádio na era da TV) [p.297-316], Paulo Cesar nos lembra que na década de 1970, as trilhas sonoras das novelas da TV Globo excluiam a música brega, optando pelo repertório da MPB. Até mesmo a trilha sonora da novela o Cafona, de Bráulio Pedroso, não incluía nenhuma música de compositores cafonas! Ele cita a analista da crítica televisiva Elisabeth Carvalho, que resume assim a consolidação do chamado "padrão global" que passaria a vigorar: ". . . um padrão estético a respeitar: pessoas com defeito físico, de ar muito miserável, sem alguns dentes na boca ou mesmo com roupas rasgadas deveriam a todo custo ser evitadas no vídeo". Paulo Cesar (p.303-304) reconhece esta posição da Globo na escolha das músicas:

Ou seja, aquela "imagem asséptica" vinha acompanhada de uma "sonoridade asséptica" - e esta era incompativel com as canções do repertório "cafona". Daí a preferência pelo repertório de artistas como Caetano Veloso e Tom Jobim. A estética da MPB, com suas dissonâncias e ambições literárias, se ajustava melhor ao projeto de se vender a ideia de um país economicamente forte, moderno e desenvolvido. Mas como uma incômoda realidade, as canções de Odair José ou de Waldik Soriano estavam ali, bem próximas, para lembrar que o Brasil, ou grande parte dele, é miserável, sim!; é subdesenvolvido, sim!; é analfabeto, sim!. E isto a emissora do Jardim Botânico queria varrer para debaixo do tapete.

0 capitulo A Cultura da brutalidade (Waldik Soriano e as músicas de rejeição social) [p.233-249] revela a voz dos oprimidos por meio canção-ícone de Waldik Soriano ("Eu não sou cachorro, não / pra viver tão humilhado. . ."), que logo se tornou uma das canções mais cantadas em todo o Brasil, e que foi escolhida por Paulo Cesar de Araújo para título do seu livro. Transcendendo a motivação original e quase cômica desta frase (uma reclamação de seu empresário, em 1972, por ter ficado esperando horas por ele no aeroporto de Natal), Eu não sou cachorro, não se tornou não apenas a voz dos que sofriam das chamadas "dores de cotovelo", mas principalmente dos oprimidos sociais.

Recorrendo às ideias de pensadores sobre o perfil soturno do brasileiro pobre e apaixonado e às histórias de vida geralmente muito difíceis dos compositores cafonas, o autor busca, no capitulo Canções sobre a tristeza brasileira (um vazio no bolso e no coração) [p.251-263], compreender socialmente porque a tristeza aparece como tema muito recorrente nesse repertório (p.264-265):

\footnotetext{
. na visão dos militares, tristes eram todos aqueles incapazes de perceber os benefícios de uma nova era de "fartura" e de "felicidade" instaurada no Brasil a partir de 1964. Não perceber a inauguração daquele novo tempo "resultaria em tristeza, em inadaptação - tal como eram não-adaptados os que insistiam em se opor ao regime militar". Portanto, mais do que nunca era preciso saudar a alegria e rechaçar a tristeza, desgraça de todos os pessimistas e derrotistas.

\begin{abstract}
. Visando estimular a alegria e o otimismo no povo brasileiro, uma das campanhas da ditadura tinha como lema a frase: "Você precisa acreditar" - ou seja, o oposto do que cantava Paulo Sérgio no sucesso Não Creio em Mais Nada. E a descrença do artista aparece em outra balada em que ele diz: "Quanta tristeza eu tenho / quanta incerteza comigo vai...". Inseridos neste contexto, o ceticismo e a melancolia do repertório "cafona" acabavam por adquirir, mesmo que não intencionalmente, um caráter transgressor e de resistência. .
\end{abstract}

Talvez o capitulo Tradição e modernidade (vertentes interpretativas da música popular brasileira) [p.335364] seja um dos mais impactantes do livro no meio acadêmico, pois acrescenta uma nova visão à percepção dicotômica sobre a música popular que se instalou na década de 1968 a 1978, e que norteia nossa percepção até hoje. Os meados da década de 1960 viram surgir duas tendências ideológicas que tentavam enquadrar a música popular brasileira em polos opostos: a tradição, 
capitaneada pela postura xenofóbica de Tinhorão (defendida em seu livro, Música popular: um tema em debate, de 1966) e a modernidade, representada por Augusto de Campos (Balanço da bossa, 1968). Restou aos cafonas ficarem espremidos entre essas duas tendências, que se consolidaram com a ajuda dos "enquadradores da memória coletiva" (críticos, pesquisadores, historiadores, sociólogos, musicólogos, produtores, curadores, animadores culturais etc.). Em meio a esse territorialismo musical, ouve uma estudada negligência de iniciativas culturais que sistematicamente excluíram os cafonas da década de 1970 no amplo acervo de fontes relacionado à música popular do Brasil. Não se via - e ainda quase não se vê - artigos, biografias, trabalhos acadêmicos, livros, coleções e enciclopédias que reconheciam a importância deste repertório varrido para debaixo do tapete das bibliotecas do país, o que inclui também quase todos os livros didáticos de história que utilizaram letras da música popular naquela época. Obras que se propuseram referenciais, como os 40 fascículos e $C D$ s das coleções MPB: Compositores (Editora Globo, 1966) e História do samba (Editora Globo, 1997), o livro 500 anos da música popular brasileira (MIS, 2001), e as três edições (1970,
1976, 1982) da coleção de fascículos de História da música popular brasileira publicadas pela Editora Abril Cultural foram particularmente omissas (p.374-375):

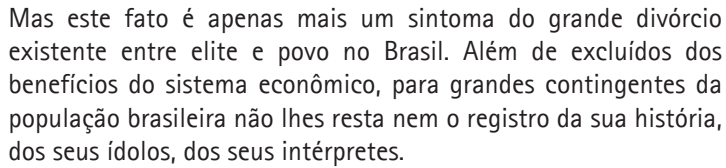

Mas este fato é apenas mais um sintoma do grande divórcio existente entre elite e povo no Brasil. Além de excluídos dos benefícios do sistema econômico, para grandes contingentes da população brasileira não Ihes resta nem o registro da sua história, dos seus ídolos, dos seus intérpretes.

Ao final da leitura, fica a clara impressão que nenhum pensador ou crítico, apesar das tentativas, soube conceituar ou localizar a música cafona no repertório musical brasileiro. Exceto o próprio Paulo Cesar de Araújo, ao dizer que é ". . . toda aquela produção musical que o público de classe media não identifica à 'tradição' ou à 'modernidade' " (p.353). Se hoje os limites entre o cafona (ou brega) e o chique (ou cult) estão cada vez mais difusos, é providencial ter o livro Eu não sou cachorro, não à mão para não perdermos de vista essa ". . . memória subterrânea, sem canais de expressão. . ." (descrita no capítulo 0 Jogo da memória (flores e canções à beira do túmulo de Paulo Sérgio, p.365-375), que tem em Paulo Cesar de Araújo o olhar mais atento.

\section{Notas}

1 Vídeo com a matéria Música brega também foi importante para a MPB por Nelson Motta postado no no youtube por Rafael Garcia em 24 de abril, 2010: http://youtu.be/qBtF00b112wn (Acesso em 20 de agosto, 2013).

2 Na sua fala recente para a série "Depoimentos para a posteridade" do MIS, gravada em 27 de julho de 2012, Paulinho da Viola revela, ao contrário de muitos compositores cafonas, sua opção pelo não engajamento político nas suas músicas: "Não fiz músicas para protestar. Nunca me senti à vontade em compor panfleto." (Jornal Metro Belo Horizonte, 27 de agosto, 2012, Edição n 226, ano 1, p. 10).

Fausto Borém é Professor Titular da Escola de Música da Universidade Federal de Minas Gerais (UFMG), onde criou o Mestrado e a Revista Per Musi. É pesquisador do CNPq desde 1994 e seus resultados de pesquisa incluem dois livros, três capítulos de livro, dezenas de artigos sobre práticas de performance e suas interfaces (composição, análise, musicologia, etnomusicologia e educação musical) em periódicos nacionais e internacionais, dezenas de edições de partituras e recitais nos principais eventos nacionais e internacionais de contrabaixo. Recebeu diversos prêmios no Brasil e no exterior como solista, teórico, compositor e professor. Acompanhou músicos eruditos como Yo-Yo Ma, Midori, Menahen Pressler, Yoel Levi, Fábio Mechetti, Luiz Otávio Santos e Arnaldo Cohen, e músicos populares como Hermeto Pascoal, Egberto Gismonti, Henry Mancini, Bill Mays, Kristin Korb, Grupo UAKTI, Toninho Horta, Juarez Moreira, Tavinho Moura, Roberto Corrêa e Túlio Mourão.Levi, Fábio Mechetti, Luiz Otávio Santos e Arnaldo Cohen, e músicos populares como Hermeto Pascoal, Egberto Gismonti, Henry Mancini, Bill Mays, Kristin Korb, Grupo UAKTI, Toninho Horta, Juarez Moreira, Tavinho Moura, Roberto Corrêa e Túlio Mourão. 